\section{- Oral Presentation 34}

TITLE: Long-term outcomes of early loading of non-submerged acid-etched implants in mandibular overdentures in older patients

AUTHORS: Nuñez Márquez E, Jiménez Guerra A, Matos Garrido N, España López A, Moreno Muñoz J, Velasco Ortega E.

Máster de Implantología Oral. Facultad de Odontología. Universidad de Sevilla.

SOURCE: Med Oral Patol Oral Cir Bucal. 2016 December 15;21(Supplement1):S14.

* doi:10.4317/medoral.17644028

http://dx.doi.org/10.4317/medoral.17644028

Introduction and Objectives: Today, oral implantology constitute a therapeutic modality in the prosthodontic treatment of edentulous geriatric patients. This study reports the long-term evaluation of edentulous patients treated with mandibular overdentures by early loading of implants with acid-etched surface.

Materials and Methods: 13 edentulous patients were treated with 45 TSA Defcon ${ }^{\circledR}$ acid-etched surface implants for prosthodontic rehabilitation with overdentures in the mandible. All implants were inserted in onestage. Implants were loaded after a healing free-loading period between 6 weeks. Clinical findings (implant and prosthodontics) were followed during 15 years.

Results: Clinical results indicate a survival and success rate of implants of $94.4 \%$. One implant were lost during the healing period. After, two implants were lost by periimplantitis. $76.9 \%$ of patients were treated with overdentures with bar $(61.5 \%$ by 4 implants and $15.4 \%$ by $3 \mathrm{im}-$ plants), and the rest of patients (23.1\%) with overdentures retained with 2 implants. 77\% of patients need attachment changes. Two overdentures were removed.

Conclusions: Clinical results of this study indicate that rehabilitation with mandibular overdentures of geriatric patients with etched-surface implants early loaded can achieve long-term successful outcomes.

\section{- Oral Presentation 35}

TITLE: Guided surgery and immediate loading in geriatric edentulous maxillary patients. A 5-year follow-up study

AUTHORS: España López A, Ortiz García I, Jiménez Guerra A, Matos Garrido N, Moreno Muñoz J, Velasco Ortega E.

Máster de Implantología Oral. Facultad de Odontología. Universidad de Sevilla.

SOURCE: Med Oral Patol Oral Cir Bucal. 2016 December 15;21(Supplement1):S14. *doi:10.4317/medoral.17644029

http://dx.doi.org/10.4317/medoral.17644029

Introduction and Objectives: The introduction of cone beam computed tomography has promoted the realization of guided surgery in dental implant treatment. The aim of this study was to present clinical results of treatment with implants inserted by the technique of guided surgery and immediate loading in edentulous jaws.

Materials and Methods: Fully edentulous maxilla patients were diagnosed by cone beam tomography and treated with 8-10 Galimplant 3D ${ }^{\circledR}$ implants for rehabilitation by the technique of guided surgery and immediate loading. Immediately after surgery a full resin provisional immediate restoration was placed. At 6 months, the final restoration was performed. The clinical follow-up period was at least 60 months of functional loading.

Results: 22 patients were treated with 194 implants. The clinical findings demonstrate an excellent clinical response of this type of protocol, free of postoperative complications in patients undergoing surgery. From an implantologic point of view, the results indicate a success rate of $98.5 \%$. Three implants were lost during the healing period with the provisional prosthesis. After a mean functioning period of 72.4 months from the final restoration, there was no late complications.

Conclusions: This study indicates that treatment with dental implants by guided surgery and immediate loading in the maxilla is a high success rate therapeutic alternative in geriatric patients.

\section{- Oral Presentation 36}

TITLE: Maxillary overdentures on implants in elderly patients. A 5 year clinical study

AUTHORS: Ortiz García I, Nuñez Márquez E, Jiménez Guerra A, Matos Garrido N, España López A, Velasco Ortega E.

Máster de Implantología Oral. Facultad de Odontología. Universidad de Sevilla.

SOURCE: Med Oral Patol Oral Cir Bucal. 2016 December 15;21(Supplement1):S14.

*doi:10.4317/medoral.17644030

http://dx.doi.org/10.4317/medoral.17644030

Introduction and Objectives: Overdentures represent a treatment option with implants for elderly patients who have been completely edentulous for a long period. The objective of the present study is to assess implant supported maxillary overdentures in completely edentulous geriatric patients.

Material and Methods: 18 completely edentulous elderly patients received maxillary overdenture treatment 